in rural hospitals. Thus we are confident that our proposals can be implemented in the more advanced centres in the places that have been specifically set up for the treatment of MDR-TB. There can be nothing special about achieving the same individualisation in the treatment for MDR-TB, as long as clinicians in those places are trained for the Bayesian-dose optimisation process. Indeed, we consider this approach less costly than losing patients to MDR and XDR-TB, and the cost of secondary cases.

O

@ERSpublications

Bayesian-dose optimisation for better and cost effective treatment of multi- and extremely drug resistant tuberculosis http://ow.ly/pN6KC

Shashikant Srivastava and Tawanda Gumbo

Office of Global Health, University of Texas Southwestern Medical Center, Dallas, TX, USA.

Correspondence: S. Srivastava, Office of Global Health, 5323 Harry Hines Blvd, University of Texas Southwestern Medical Center, Dallas, Texas -75390-8507, TX, USA. E-mail: shashi.kant@utsouthwestern.edu

Received: May 112013 | Accepted: May 142013

Conflict of interest: None declared.

\title{
References
}

1 Migliori GB, Sotgiu G, Gandhi NR, et al. Drug resistance beyond extensively drug-resistant tuberculosis: individual patient data meta-analysis. Eur Respir J 2013; 42: 169-179.

2 Srivastava S, Peloquin CASG, Migliori GB. Therapeutic drug management: is it the future of MDR-TB treatment? Eur Respir J 2013; 42: 1449-1453.

3 Akkerman AO, Van Altena R, Klinkenberg T, et al. Drug concentration in lung tissue in multidrug resistant tuberculosis. Eur Respir J 2013; 42: 1750-1752.

4 Gumbo T. New susceptibility breakpoints for first-line antituberculosis drugs based on antimicrobial pharmacokinetic/pharmacodynamic science and population pharmacokinetic variability. Antimicrob Agents Chemother 2010; 54: 1484-1491.

5 Gumbo T, Siyambalapitiyage Dona CSW, Leef R. Pharmacokinetics-pharmacodynamics of pyrazinamide in a novel in vitro model of tuberculosis for sterilizing effect: a paradigm for faster assessment of new antituberculosis drugs. Antimicrob Agents Chemother 2009; 53: 3197-3204.

6 Gumbo T, Louie A, Deziel MR, et al. Selection of a moxifloxacin dose that suppresses drug resistance in Mycobacterium tuberculosis, by use of an in vitro pharmacodynamic infection model and mathematical modeling. J Infect Dis 2004; 190: 1642-1651.

7 Srivastava S, Pasipanodya JG, Meek C, et al. Multidrug-resistant tuberculosis not due to noncompliance but to between-patient pharmacokinetic variability. J Infect Dis 2011; 204: 1951-1959.

8 Bolhuis MS, Altena R, van Soolingen D, et al. Clarithromycin increases linezolid exposure in multidrug-resistant tuberculosis patients. Eur Respir J 2013; 42: 000-000.

9 Sotgiu G, Centis R, D'Ambrosio L, et al. Efficacy, safety and tolerability of linezolid containing regimens in treating MDR-TB and XDR-TB: systematic review and meta-analysis. Eur Respir J 2012; 40: 1430-1442.

10 Haverkamp W, Kruesmann F, Fritsch A, et al. Update on the cardiac safety of moxifloxacin. Curr Drug Saf 2012; 7: $149-163$.

\section{MicroRNAs and pulmonary hypertension}

\author{
To the Editor:
}

MicroRNAs have emerged as important posttranscriptional regulators of gene transcription. The interesting review by RUPANI et al. [1] on microRNAs in respiratory diseases is, thus, accurately timed. We use this opportunity to additionally mention the role of microRNAs in pulmonary hypertension, which has been investigated both in experimental models and in human disease and, as recently reviewed in the European Respiratory Journal [2], might be of pathogenetic relevance for pulmonary hypertension. Caruso et al. [3], for example, described alterations in the expression of dicer, which is one of the most important microRNA processing enzymes, probably explaining the reduced expression levels of several microRNAs in patients with pulmonary hypertension. Some of these, such as miR-150 [4], have been described as independent predictors for an adverse outcome. Others, including miR-204 [5] have been linked to important signalling pathways in pulmonary arterial smooth muscle cells. Finally, our own work, has identified the microRNA cluster 17/92 as directly targeting the bone morphogenetic protein receptor type II [6], which, as shown by successful inhibition by antagomirs in vivo $[7,8]$, could be a causative therapeutic approach for the vascular remodelling of pulmonary arteries. 


\section{@ERSpublications}

The importance of microRNAs in respiratory diseases includes their pathogenetic role and the use as biomarkers in $\mathrm{PH}$ http://ow.ly/o3S8c

Matthias Brock, Silvia Ulrich and Lars Christian Huber

Division of Pulmonology, University Hospital of Zurich, Zurich, Switzerland.

Correspondence: L.C. Huber, University Hospital of Zurich, Division of Pulmonology, Rämistrasse 100, 8091 Zurich, Switzerland. E-mail: Lars.Huber@usz.ch

Received: March 042013 | Accepted after revision: March 082013

Support statement: The project "Role of microRNAs in pulmonary hypertension: diagnosis and treatment" is supported by the Swiss National Science Foundation (31003A_144212).

Conflict of interest: None declared.

\section{References}

1 Rupani H, Sanchez-Elsner T, Howarth P. MicroRNAs and respiratory diseases. Eur Respir J 2013; 41: 695-705.

2 Voelkel NF, Gomez-Arroyo J, Abbate A, et al. Pathobiology of pulmonary arterial hypertension and right ventricular failure. Eur Respir J 2012; 40: 1555-1565.

3 Caruso P, MacLean MR, Khanin R, et al. Dynamic changes in lung microRNA profiles during the development of pulmonary hypertension due to chronic hypoxia and monocrotaline. Arterioscler Thromb Vasc Biol 2010; 30: 716-723.

4 Rhodes CJ, Wharton J, Boon RA, et al. Reduced microRNA-150 is associated with poor survival in pulmonary arterial hypertension. Am J Respir Crit Care Med 2013; 187: 294-302.

5 Courboulin A, Paulin R, Giguère NJ, et al. Role for miR-204 in human pulmonary arterial hypertension. J Exp Med 2011; 208: 535-548.

6 Brock M, Trenkmann M, Gay RE, et al. Interleukin-6 modulates the expression of the bone morphogenic protein receptor type II through a novel STAT3-microRNA cluster 17/92 pathway. Circ Res 2009; 104: 1184-1191.

7 Pullamsetti SS, Doebele C, Fischer A, et al. Inhibition of microRNA-17 improves lung and heart function in experimental pulmonary hypertension. Am J Respir Crit Care Med 2012; 185: 409-419.

8 Brock M, Samillan VJ, Trenkmann M, et al. AntagomiR directed against miR-20a restores functional BMPR2 signalling and prevents vascular remodelling in hypoxia-induced pulmonary hypertension. Eur Heart J 2012 [In press DOI: 10.1093/eurheartj/ehs060].

Eur Respir J 2014; 43: 313-314 | DOI: 10.1183/09031936.00039113 | Copyright @eERS 2014 